\title{
New Formation Mechanism of Allylic Trithiocarbonates from Sodium $O$-(2-Alkenyl) Dithiocarbonates via Sequential Pericyclic Reactions: Density Functional Theory Study
}

\author{
Masashi Eto, ${ }^{b}$ Koki Yamaguchi, ${ }^{a}$ Yasuyuki Yoshitake, ${ }^{a}$ and Kazunobu Harano ${ }^{*, a}$ \\ ${ }^{a}$ Faculty of Phamaceutical Sciences, Sojo University; 4-22-1 Ikeda, Kumamoto 869-1404, Japan: and ${ }^{b}$ Liberal Arts \\ Education Center, Aso Campus, Tokai University; 5435 Kawayo, Minami-Aso, Kumamoto 869-1404, Japan. \\ Received August 3, 2010; accepted September 2, 2010; published online September 3, 2010
}

\begin{abstract}
Density functional theory (DFT) calculations at the B3LYP/6-31G(d) level demonstrated that sodium $O$-(3phenylallyl) dithiocarbonate undergoes [3,3]-sigmatropic rearrangement to sodium $S$-(1-phenylallyl) dithiocarbonate, which then isomerizes to the more thermodynamically stable sodium $S$-(3-phenylallyl) dithiocarbonate. The calculations also showed that sodium 2-alkenyl trithiocarbonates and their esters are more labile towards the allylic rearrangement.
\end{abstract}

Key words dithiocarbonate; trithiocarbonate; thione-to-thiol rearrangement; [3,3]-sigmatropic rearrangement; density functional theory calculation

Allylic thiols and related sulfur compounds are very important in the fields of biological activity, ${ }^{1)}$ and because of their synthetic utility as building blocks of organic compounds. ${ }^{2-5)}$ We previously reported a one-pot preparation of precursors of allylic thiols, in which heating a suspension of sodium hydride in benzene containing an allylic alcohol (2alkenol) and an excess of carbon disulfide gave the corresponding di(2-alkenyl)trithiocarbonate (3) in good yields. ${ }^{6}$ Allylic thiols can be generated from 3 by heating with ethanolamine (Chart 1). ${ }^{7}$ In this reaction, sodium 2-alkenyl trithiocarbonate (3-Na) (a precursor of 3) was formed via thermal rearrangement of sodium $O$-(2-alkenyl) dithiocarbonate (1-Na) to $S$-(2-alkenyl) dithiocarbonate (2-Na) followed by the reaction with an excess of carbon disulfide. $\left.{ }^{6}\right)$ The thione-to-thiol rearrangement of sodium $O$-(2-alkenyl) dithiocarbonate (1-Na) was thought to proceed via an ionic mechanism to give the thermodynamically stable allylic isomer. However, the rearrangement was highly regioselective for an ionic reaction, and allylic isomers were not observed in every case (see Chart 1). The reaction took place in a non-

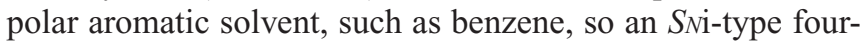
membered cyclic mechanism is more plausible than a carbo-
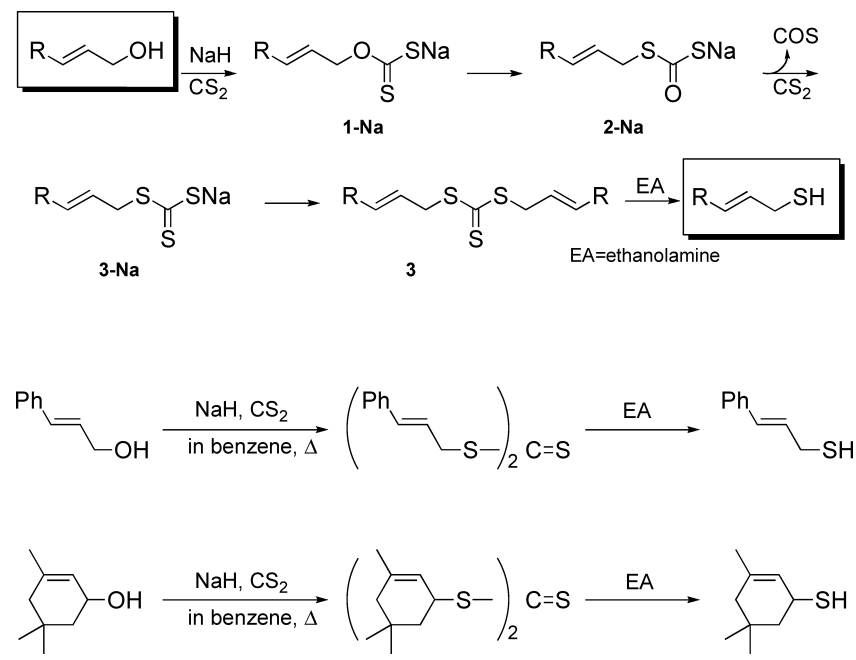

Chart 1 nium ion mechanism.

These considerations prompted us to investigate the details of the thione-to-thiol rearrangement pathway using computer simulation techniques. ${ }^{8)}$

\section{Results and Discussion}

First, we tried to locate the transition-state (TS) structure

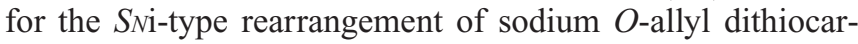
bonate (1a-Na) (Chart 2).

During the TS structure optimization by the density functional theory (DFT) method, ${ }^{9)}$ using structural models, we

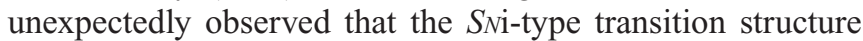
model $\left(\mathbf{T S}_{\mathrm{a}}\right)$ was transformed to the one of $S_{\mathrm{Ni}}{ }^{\prime}$-type model $\left(\mathbf{T S}_{\mathbf{b}}\right)$ (i.e. a [3,3]-sigmatropic rearrangement). The calculated geometries and energies for both $\mathbf{T S}_{\mathbf{a}}$ and $\mathbf{T S}_{\mathbf{b}}$ are depicted in Fig. 1.

The reaction barrier for the $S_{N \mathrm{i} \text {-type reaction is calculated }}$ to be $41.0 \mathrm{kcal} / \mathrm{mol}$, which is higher than that for the [3,3]sigmatropic rearrangement whose reaction barrier is predicted to be $28.2 \mathrm{kcal} / \mathrm{mol}$. This suggests that allylic rearrangement of the sodium $O$-allyl dithiocarbonate (1a-Na) proceeds easily in boiling benzene. This assumption is supported by the fact that the experimental reaction barrier height for $O$-cinnamyl $S$-methyl dithiocarbonate in $n$-hexadecane is $26.2 \mathrm{kcal} / \mathrm{mol},{ }^{10)}$ close to the B3LYP/6-31G(d)-calculated value of $25.1 \mathrm{kcal} / \mathrm{mol}^{11)}$ Calculations using anion models in the absence of sodium ions gave essentially the same results. ${ }^{12)}$ The subsequent calculations were therefore performed on dithiocarbonate anion models.

Interestingly, the DFT calculations indicate that the $S$-allyl

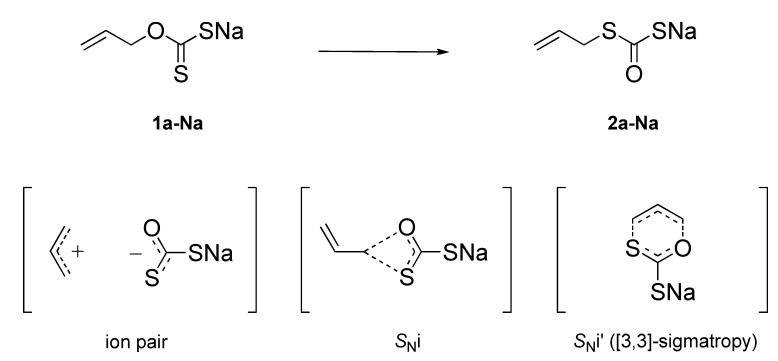

Chart 2 
dithiocarbonate anion (2a) undergoes a [3,3]-sigmatropic rearrangement to give the allylically isomeric product (Fig. 2). The reaction barrier was calculated to be $27.3 \mathrm{kcal} / \mathrm{mol}$, slightly lower than that for rearrangement of the $O$-allyl dithiocarbonate anion (1a)
Similar calculations were performed using an unsymmetrical substrate, i.e., the $O$-cinnamyl dithiocarbonate anion (1b) and the $S$-cinnamyl dithiocarbonate anion (2b) (Fig. 3). The reaction barrier $(\Delta E)$ for the thione-to-thiol rearrangement is estimated to be $26.8 \mathrm{kcal} / \mathrm{mol}$, the resonance energy of

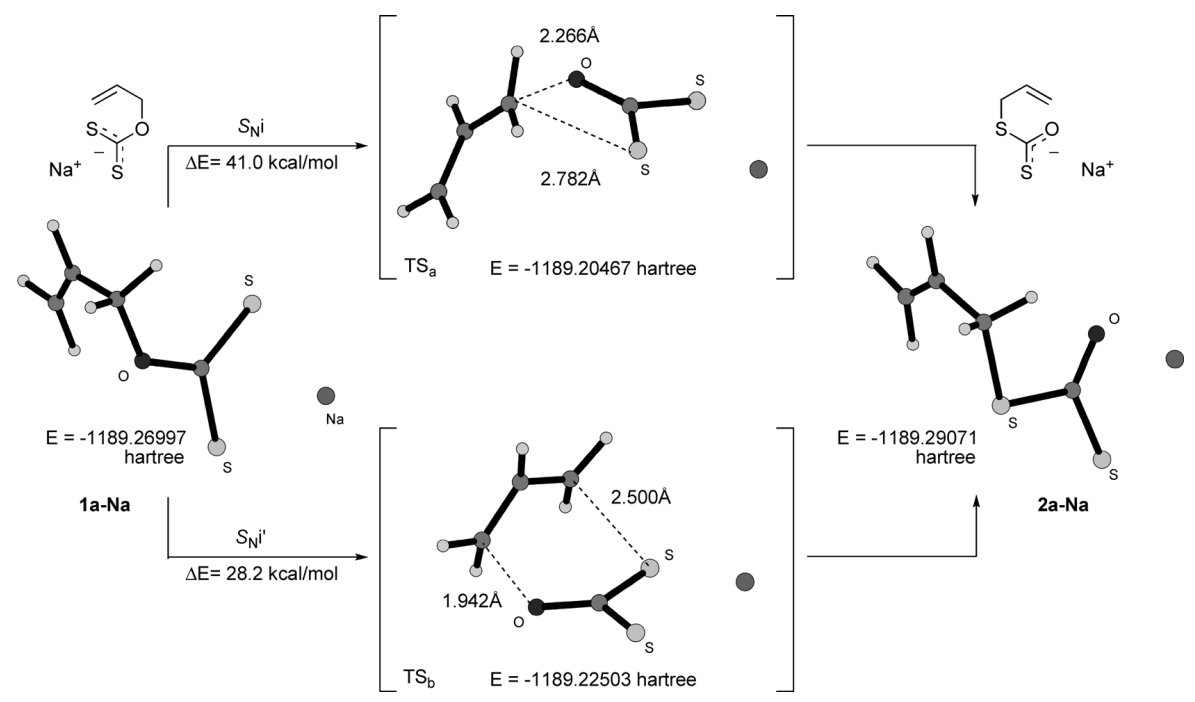

Fig. 1. DFT-Calculated Geometries and Energies of TS at B3LYP/6-31G(d) Level for the Thione-to-Thiol Rearrangemet of Sodium O-Allyl Dithiocarbonate $(\mathbf{1} \mathbf{a}-\mathrm{Na})$

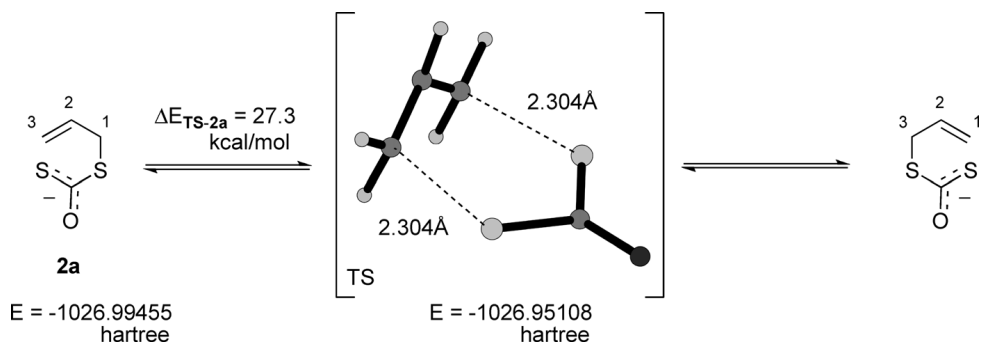

Fig. 2. B3LYP/6-31G(d) TS Structure for the Reaction of S-Allyl Dithiocarbonate Anion (2a)

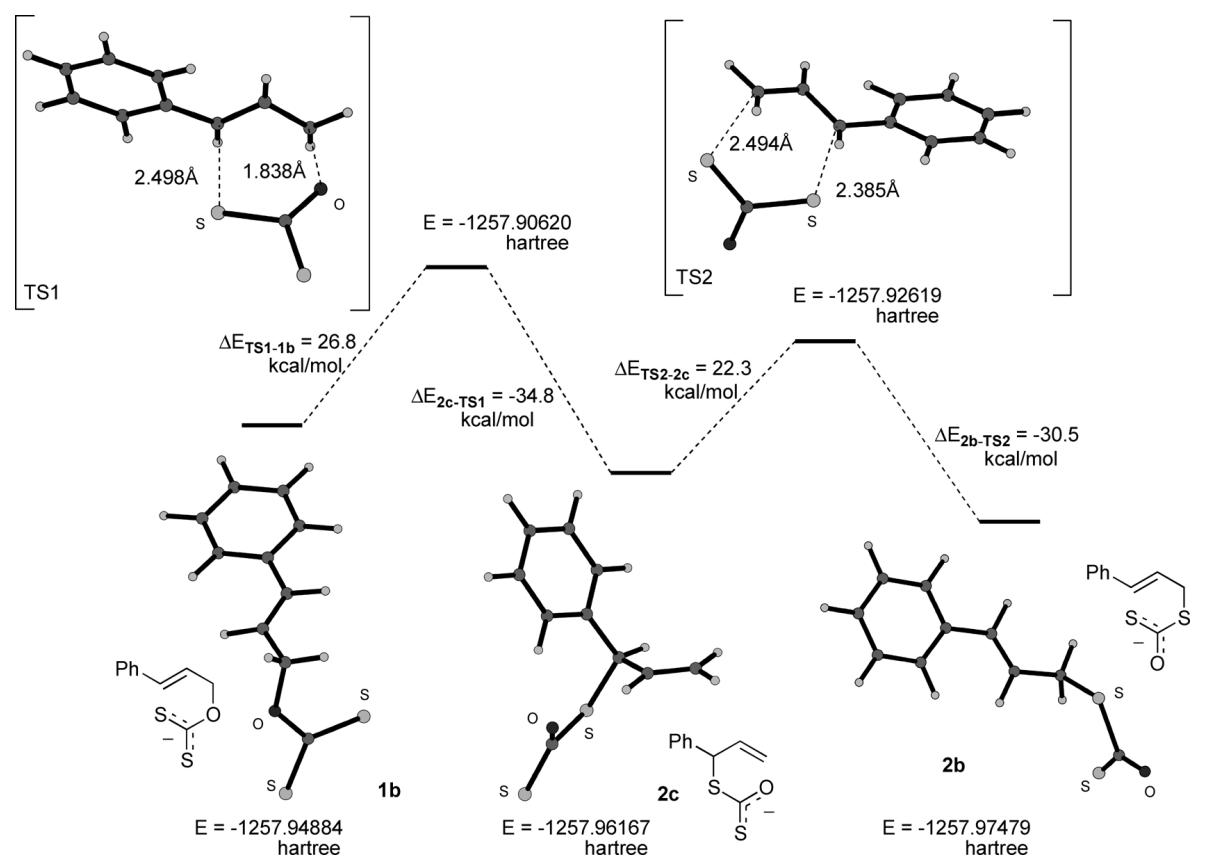

Fig. 3. DFT-Calculated Potential Energy Profile and Geometries for the Sequential [3,3]-Sigmatropic Rearrangement of O-Cinnamyl Dithiocarbonate Anion (1b) 
A)
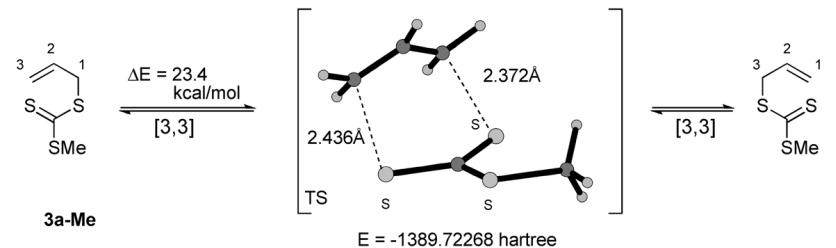

B)

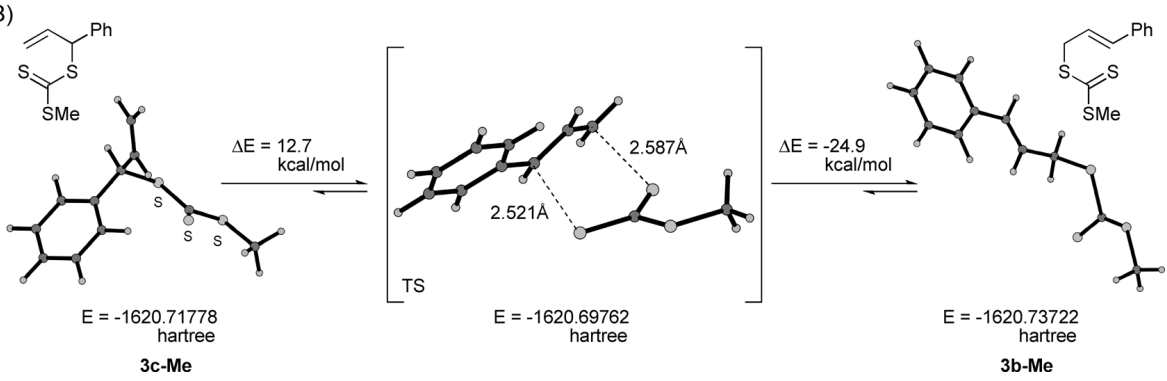

Fig. 4. DFT-Calulated Reaction Barriers for the Isomerization of 2-Alkenyl Methyl Trithiocarbonates

(A) Allyl methyl trithiocarbonate (3a-Me). (B) 1-Phenylallyl methyl trithiocabonate (3c-Me).
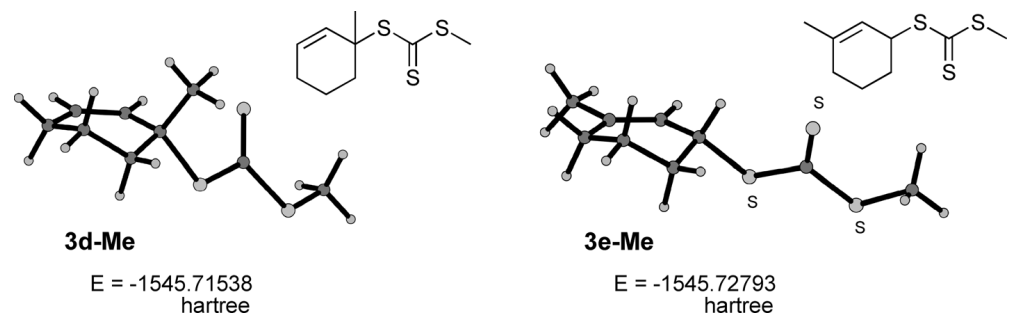

Fig. 5. Ground-State Energies and Geometries of 1-Methylcyclohex-2-enyl Methyl Trithiocarbonate (3d-Me) and 3-Methylcyclohex-2-enyl Methyl Trithiocarbonate (3e-Me)

$\mathrm{Ph}-\mathrm{CH}=\mathrm{CH}-$ being lost in the allylic isomerization. The rearranged product $\mathbf{2 c}$ is thought to isomerize readily to the $S$ cinnamyl dithiocarbonate anion $(\mathbf{2 b})$. The calculated reaction barrier is $22.3 \mathrm{kcal} / \mathrm{mol}$, lowered by the resonance stabilization. These results strongly suggest that the $S$-(2-alkenyl) dithiocarbonate anion is equilibrated by a [3,3]-sigmatropic rearrangement and that the structure of the isolated product depends on the relative thermodynamic stabilities of the allylic isomers.

This consideration is also applicable to the [3,3]-sigmatropic rearrangement of allylic trithiocabonates. The calculated reaction barrier for $S$-allyl $S$-methyl trithiocarbonate (3a-Me) is $23.4 \mathrm{kcal} / \mathrm{mol}$ (Fig. 4A). In the phenyl-substituted allyl derivative (3c-Me), the exclusive formation of $S$-cinnamyl $S$-methyl trithiocarbonate (3b-Me) can be predicted from the DFT calculation data. The reaction barrier for the isomerization of 1-phenylallyl methyl trithiocabonate (3cMe) to cinnamyl methyl trithiocarbonate (3b-Me) is $12.7 \mathrm{kcal} / \mathrm{mol}$, whereas the barrier for the reverse isomerization is $24.9 \mathrm{kcal} / \mathrm{mol}$ (Fig. 4B). The relative stabilities of 3cMe and 3b-Me are affected by resonance stabilization in accordance with experimental result. ${ }^{6)}$

3,5,5-Trimethylcyclohex-2-enol was subjected to a similar reaction to give the corresponding trithiocarbonate, without skeletal changes (Chart 1). ${ }^{6}$ The DFT calculation supported the relative stabilities of the allylic isomers. 3-Methylcyclohex-2-enyl methyl trithiocarbonate (3e-Me) is $8.0 \mathrm{kcal} / \mathrm{mol}$ more stable than 1-methylcyclohex-2-enyl methyl trithiocarbonate (3d-Me) (Fig. 5).

Allylic thiols can be regioselectively prepared by choosing

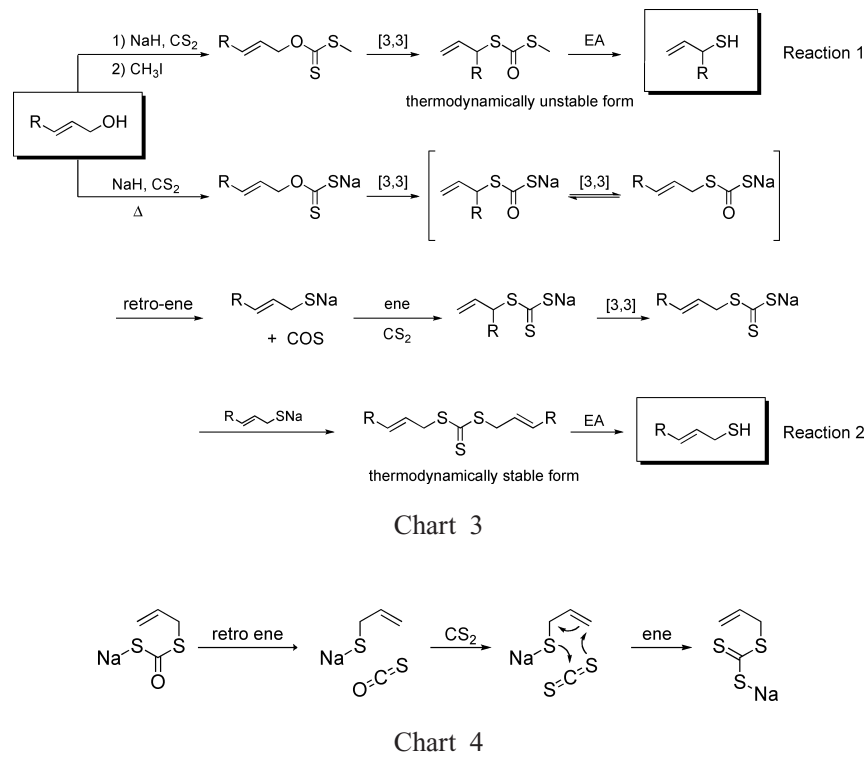

a suitable preparation method (reaction 1 or 2 in Chart 3). Thermodynamically unstable allylic thiols can be prepared by $[3,3]$-sigmatropic rearrangement of allylic xanthates under mild and low-temperature conditions ${ }^{10,13-16)}$; stable allylic thiols are readily prepared by a procedure based on allylic trithiocarbonates, without using allylic halides.

In the latter procedure, the transformation from the dithiocarbonate anion to the trithiocarbonate anion is considered to be caused by sequential retro-ene $[2 \sigma+2 \sigma+2 \pi]$ and ene $[2 \pi+2 \pi+2 \sigma]$ reactions (Chart 4$),{ }^{17)}$ in which the intermedi- 
ary compound $\left(\mathrm{RCH}=\mathrm{CHCH}_{2} \mathrm{SNa}\right)$ can attack the thiocarbonyl carbon atom of 3-Na to give di(2-alkenyl)trithiocarbonate (3) and $\mathrm{Na}_{2} \mathrm{~S}$.

In conclusion, DFT calculations provided a reliable theoretical evidence for the [3,3]-sigmatropic rearrangement of allylic $O, S$ - and $S, S$-dithiocarbonates and trithiocarbonates, for both the sodium salts and the alkyl esters. Use of a pericyclic reaction of the thione esters provides a simple and efficient method for regioselective and stereoselective synthesis of allylic thiols which are difficult to prepare by other methods.

\section{Experimental}

Molecular Orbital (MO) Calculation The MO calculations were performed by density functional theory (DFT) based ab initio method at the B3LYP/6-31G(d) level using the Linda-Gaussian03 program package. ${ }^{9)}$ The input geometries of the ground states (GS) and the transition states (TS) were obtained by semi-empirical MO calculations. ${ }^{18-20)}$ Zero point energy (ZPE) corrections were scaled by $0.9804{ }^{21)}$ All of the calculations were performed on an HIT PC cluster of 4-16 processors (Pentium 4, 3.0 MHz) or an HIT Linux cluster server (4 CPU) made up of dual $1.6 \mathrm{GHz}$ Itanium 2 processors.

\section{References and Notes}

1) Lonsdale D., J. Nutr. Environ. Med., 2, 305-311 (1991).

2) Williams D. R., Barner B. A., Nishitani K., Phillips J. G., J. Am. Chem. Soc., 104, 4708-4710 (1982).

3) Fujii I., Koreyuki M., Kanematsu K., Chem. Pharm. Bull., 36, 17501757 (1988).

4) Chambers M. S., Thomas E. J., Williams D. J., J. Chem. Soc. Chem. Commun., 1987, 1228-1230 (1987).

5) Chambers M. S., Thomas E. J., J. Chem. Soc., Perkin Trans. 1, 1997, 417-431 (1997)

6) Harano K., Taguchi T., Yakugaku Zasshi, 93, 804-810 (1973).

7) Taguchi T., Kiyoshima Y., Komori O., Mori M., Tetrahedron Lett., 10, 3631-3634 (1969).

8) A part of this work was introduced in a review of Studies on Cascade Reactions of Unsaturated Xanthates and Related Reactions: Computerassisted Molecular Design and Analysis of Reaction Mechanisms: Harano K., Yakugaku Zasshi, 125, 469—489 (2005).
9) Gaussian 03, Revision C.02, Frisch M. J., Trucks G. W., Schlegel H. B., Scuseria G. E., Robb M. A., Cheeseman J. R., Montgomery J. A. Jr., Vreven T., Kudin K. N., Burant J. C., Millam J. M., Iyengar S. S., Tomasi J., Barone V., Mennucci B., Cossi M., Scalmani G., Rega N., Petersson G. A., Nakatsuji H., Hada M., Ehara M., Toyota K., Fukuda R., Hasegawa J., Ishida M., Nakajima T., Honda Y., Kitao O., Nakai H., Klene M., Li X., Knox J. E., Hratchian H. P., Cross J. B., Bakken V., Adamo C., Jaramillo J., Gomperts R., Stratmann R. E., Yazyev O., Austin A. J., Cammi R., Pomelli C., Ochterski J. W., Ayala P. Y., Morokuma K., Voth G. A., Salvador P., Dannenberg J. J., Zakrzewski V. G., Dapprich S., Daniels A. D., Strain M. C., Farkas O., Malick D. K., Rabuck A. D., Raghavachari K., Foresman J. B., Ortiz J. V., Cui Q., Baboul A. G., Clifford S., Cioslowski J., Stefanov B. B., Liu G., Liashenko A., Piskorz P., Komaromi I., Martin R. L., Fox D. J., Keith T., Al-Laham M. A., Peng C. Y., Nanayakkara A., Challacombe M., Gill P. M. W., Johnson B., Chen W., Wong M. W., Gonzalez C., Pople J. A., Gaussian, Inc., Wallingford CT, 2004.

10) Harano K., Taguchi T., Chem. Pharm. Bull., 23, 467-472 (1975).

11) Eto M., Kubota S., Nakagawa H., Yoshitake Y., Harano K., Chem. Pharm. Bull., 48, 1652-1659 (2000).

12) The B3LYP/6-31G(d) calculated ground-state energies and reaction barrier are as follows: $O$-allyl dithiocarbonate anion (1a): $E=$ -1026.97441 hartree; $\mathbf{T S}_{\mathbf{b}}: E=-1026.93002$ hartree; $S$-allyl dithiocarbonate anion (2a): $E=-1026.99455$ hartree; reaction barrier: $27.9 \mathrm{kcal} / \mathrm{mol}$

13) Harano K., Taguchi T., Yakugaku Zasshi, 94, 1495-1502 (1974).

14) Harano K., Taguchi T., Chem. Pharm. Bull., 20, 2348-2356 (1972).

15) Harano K., Taguchi T., Chem. Pharm. Bull., 20, 2357-2365 (1972).

16) The B3LYP/6-31G(d) calculated energy profile for the $S_{N i}{ }^{\prime}$-type rearrangement of $O$-allyl $S$-methyl dithiocabonate are as follows: $O$-allyl $S$-methyl dithiocarbonate (GS1): $E=-1066.78661$ hartree; transitionstate of $S N \mathrm{i}^{\prime}$ (TS): $E=-1066.74641$ hartree; $S$-allyl $S$-methyl dithiocarbonate (GS2): $E=-1066.80765$ hartree; $\Delta E_{\mathrm{TS}-\mathrm{GS} 1}=25.2 \mathrm{kcal} / \mathrm{mol}$; $\Delta E_{\mathrm{GS} 2-\mathrm{GS} 1}=-13.2 \mathrm{kcal} / \mathrm{mol}$. These indicate that $S$-allyl $S$-methyl dithiocarbonate is more thermodynamically stable than $O$-allyl $S$ methyl dithiocarbonate.

17) Eto M., Nishimoto M., Kubota S., Matsuoka T., Harano K., Tetrahedron Lett., 37, 2445-2448 (1996).

18) Stewart J. J. P., J. Am. Chem. Soc., 107, 3902-3909 (1985).

19) Stewart J. J. P., J. Comp. Chem., 10, 209-220 (1989).

20) Stewart J. J. P., J. Comp. Chem., 10, 221-264 (1989).

21) Scott A. P., Radom L., J. Phys. Chem., 100, 10502-10513 (1996). 